\title{
Correction to: Acute and chronic neuromuscular adaptations to local vibration training
}

\author{
Robin Souron ${ }^{1} \cdot$ Thibault Besson $^{1} \cdot$ Guillaume Y. Millet $^{2} \cdot$ Thomas Lapole $^{1}$
}

Published online: 7 December 2017

(c) Springer-Verlag GmbH Germany, part of Springer Nature 2017

\section{Correction to:}

Eur J Appl Physiol (2017) 117:1939-1964

https://doi.org/10.1007/s00421-017-3688-8

The author would like to correct the reference in the publication of the original article. The corrected reference is given below for your reading.
Costa PR, Sá-Caputo DC, Arnóbio A, Pacheco R, Kutter C, Costa R, Giehl PM, Paiva DN, Marin PJ, Salmon JR, Tillman M, Bernardo-Filho M (2014) Whole-body vibration and benefits for people with osteoarthritis: a systematic review. Int J Med Med Sci 6(9):201-210.

The original article can be found online at https://doi. org/10.1007/s00421-017-3688-8.

Thomas Lapole

thomas.lapole@univ-st-etienne.fr

1 Univ Lyon, UJM Saint-Etienne, Laboratoire Interuniversitaire de Biologie de la Motricité, EA 7424, 42023 Saint-Etienne, France

2 Human Performance Laboratory, Faculty of Kinesiology, University of Calgary, Calgary, Canada 